major installation in the Institute is an electron beam pattern generator.

Two facilities, in Amsterdam and Nijmegen, for high magnetic fields also coordinate their activities across a broad front. Successful national research programmes exist in the fields of integrated circuit technology, optoelectronics and high temperature superconductors. In addition to the FELIX free electron facility, a smaller and more modest activity in the area has recently been launched by the technical universities of Enschede and Eindhoven.

\section{Employment}

Graduates with both first degrees and doctorates encounter little difficulty in finding positions. Over the years, the number of young physicists has just about kept pace with the demand. The relatively constant requirements of the large multinational companies and the traditional ease with which the Dutch go abroad are important factors in creating this stable situation.

However, during the last few years the situation in the "education" market has rapidly deteriorated. University courses in teacher training are right now almost empty. A real problem is in the making. The image of the teaching profession is poor, mainly because of low starting salaries for graduates and permanent unrest in the education system owing to difficulties with the budget. The government claims to be aware of the disturbing situation but still does not provide adequate funding to do something about it.

\section{The Physical Society}

The Netherlands has a single physical society called The Netherlands' Physical Society (or Nederlandse Natuurkundige Vereniging) founded in 1921 by Lorentz, Zeeman, Kamerlingh Onnes and others. Of the 8000 or so working physicists in the Netherlands, about 3500 are members. The main activities of the Society involve promoting the interests of the Dutch physics community through contacts with national and international societies and with university and government officials, organizing a general Spring Meeting and meetings of the Society's 16 divisions and sections, publishing two periodicals and maintaining two chairs (at the Universities of Amsterdam and Delft).

The overall image of physics in The Netherlands is that of an internationally oriented, productive, healthy and enthusiastic community - features that everybody hopes to have shown you in Amsterdam this month.

\title{
AGOR Takes Shape
}

AGOR, the Accelerator Groningen - Orsay, as the acronym suggests is a joint Dutch-French project to build a superconducting cyclotron with the unique capability to accelerate both protons (to $100-200 \mathrm{MeV}$ ) and heavy ions up to uranium (to 6-100 MeV/nucleon). Representing the largest ever collaboration of its type, the machine is being built at IPN, the Institute of Nuclear Physics, Orsay in France. It will be installed at KVI, the Nuclear Accelerator Institute in Groningen, The Netherlands where it will be used by physicists from both countries. The superconducting magnet coils and their cryogenic systems are presently being fabricated ready for field mapping starting in mid-1991, and the first beam tests at Orsay in 1993.

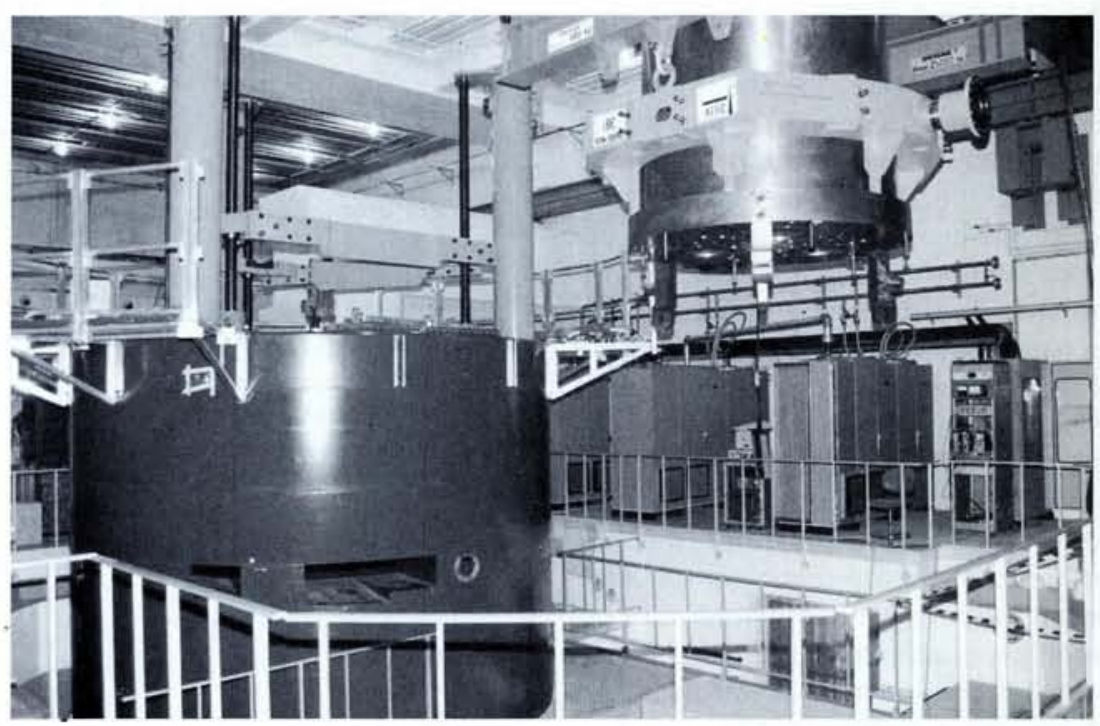

The photo shows the AGOR cyclotron under construction at Orsay. To the right is one of the two pole pieces of the superconducting magnet structure. It is $1.9 \mathrm{~m}$ in diameter and has three cylindrical spaces for the RF resonators separating three magnetic sectors. Not visible is the complicated form of the pole face which has been optimised for the production of the very steep radial field gradient that is required to allow protons as well as other ions to be accelerated in a stable configuration. A pair of superconducting coils, $2.4 \mathrm{~m}$ in diameter, weighing 25 tonnes and wound using $\mathrm{NbTi}$ conductor, will be placed around each of the pole pieces that are separated at the median plane by a gap of $70 \mathrm{~mm}$ between opposing magnet sectors.

To the left is shown the $4.4 \mathrm{~m}$ diameter cylindrical iron yoke which will encircle the two sets of pole/coil assemblies. Rectangular and square apertures around the median plane are for the beam exit (dummy exits are not visible) and for inserting instrumentation. The $200 \mathrm{~mm}$ diameter hole is for one of the three radial tie rods that support the two pole/coil assemblies; other tie rods pass vertically.

Racks of cabinets for RF power supplies for the resonators that work at the relatively high frequency of $62 \mathrm{MHz}$ (40 MHz is more usual) are found in the background.

H.E. Schreuder, KVI, Groningen

\section{Balances in the Atmosphere and the Energy Problem Editor: E.W.A. Lingeman \\ Proceedings of the 59th WE-Heraeus Seminar Bad Honnef, FRG / 4-7 February 1990}

Organized in co-operation with the EPS Action Committee on Physics and Society

A. Tartaglia: Induced Critical Conditions H. Grassl: The Greenhouse Effect K.Ya. Vinnikov: Anthropogenic Change A.P.M. Baede: Greenhouse Impact R. Kümmel: Removal, Disposal of $\mathrm{CO}_{2}$ D.O. Hall: $\mathrm{CO}_{2}$ Cycling

\section{K. Heinloth: Summary}

Orders in writing to EPS Secretariat, Geneva with payment (cheques drawn on a Swiss bank) or transfer:

Société de Banque Suisse, CP, CH-1211 Geneva 11, Acc. No.: 164.899

Swiss Post Office, Acc. No.: CCP 12-19107-4
S.G. Zvenigorodsky: Numerical Simulations A.S. Silbergleit: Thermodynamics A.K. Schatz: Nuclear Energy W. Turkenburg: Photovoltaic Energy C. Marchetti: Energy Without $\mathrm{CO}_{2}$ G. Benedek: The EPS and UNESCO

PRICE: IOM's - $60 \mathrm{Sfr}$ other - $120 \mathrm{Sfr}$ 